\title{
Validating the Power of Bilingualism on Conflict Regulation, Cognitive Control and Recognition of Iranian Primary School Students
}

\author{
Negin Aalaei* \\ Islamic Azad University, Sarab Branch, Iran
}

Corresponding Author: Negin Aalaei, E-mail: Ne.aalaei@yahoo.com.sg

\section{ARTICLE INFO}

Article history

Received: February 27, 2018

Accepted: April 09, 2018

Published: September 01, 2018

Volume: 7 Issue: 5

Advance access: July 2018

Conflicts of interest: None

Funding: None

\begin{abstract}
The purpose of the study is to measure the effects of bilingualism on conflict regulation, cognitive control and recognition among primary school children. This study is a description study on primary school students in the city of Parse Abab, the branch of Ardabil, Iran that is studying in the school year 94-95. The sample consists of 120 students which include 60 boys and 60 girls. The samples were selected by randomly. In this study the questionnaires and tasks based on cognition and recognition was used. The questionnaires were collected from both groups were analyzed by SPSS software and SPSS software was used to measure mean, median, standard deviation, significance level, etc., and to analyze the hypotheses of variance by (MANOVA). The results showed that the bilingualism has direct effect on the conflict regulation, cognitive control and recognition among primary school children. There is significant difference among bilingual and monolingual students performance. To the best of our knowledge, this is the first study to examine the temporal aspects of bilingualism in relation to the conflict regulation, cognitive control and recognition of students in primary schools in bilingual areas. Other studies try to examines the effect of bilingualism on only one of the variables but this study consider three variable in order to show clearly its effect on each of the variables separately.
\end{abstract}

Key words: Bilingualism, Conflict Regulation, Cognitive Control, Recognition Control, Bilingual Students, Primary School Students

\section{INTRODUCTION}

It is estimated that half of the world's population at the beginning of the $21^{\text {st }}$ century was bilingual. The average percentage of individuals bilingualism can differs in the result of their dependence or independence on how researchers or society may define bilingualism and the complex relationship between different languages. According to Tugade, M.M., \& Frederickson, B.L. (2002) bilingualism is a phenomenon that exists and can be seen overtly in all countries around the world. Bilingualism can be spread in all different classes of society which could include all members of that society among individuals.

There is no fix and pure definition for bilingualism and bilingualism can includes both trilingual's and multilingualism. The main goal of the study is to consider the effects of bilingualism on conflict regulation, cognitive control and recognition among primary school students. This study aims to determine the relationship between being bilingual and its direct effect on student's conflict regulation, control of their cognition and recognition. The already status of comprehension about bilingualism and being bilingual can be traced to three different principal areas in this research. The first principle in this study is the question of the relationship of bilingualism to conflict regulation. The second principle is the study of relationship between bilingualism and cognitive controls. The third is a level of analysis issue on the effect of bilingualism recognition among primary school students (Yoo SH, Matsumoto D, LeRoux JA. 2006).

\section{LITERATURE REVIEW}

Bilingualism is the individual ability to use two or more languages coordinately or compound. Individuals with different bilingual features may be divided as bilingual and this can bring some problems in this area. Bilingualism can be classified by their ability and function in two languages that allows to the speaker to function in that language and also allow them to appear as native-like speakers of two languages (Barisi \& Ghafari. 2006).

Individuals can describe themselves as bilingual but their proficiency can be only in one special area than other areas. For example one may have complete ability to converse and communicate orally in society or other may be component in writing in academic fields and so on. Different individuals may have various degree of proficiency in two or more languages. Different conditions may be cause of being bilingual. Bilingualism can be sequential or imultaneous 
(Thompson, R. A. 1991). Simultaneous bilingualism can be product of learning the language in schools and by learning and using two different languages simultaneously. Sequential bilingualism can happen in second stage of life by learning a second language after learning their first language. The criteria of bilingualism and being bilingual may require different range of proficiencies of individuals, their abilities and contexts for individuals. (Bull, R. Espy, K. A. \& Wiebe, S. A. 2008).

With expressing an example we can prove this claim. For instance a young child entering to primary school may be called bilingual but it may be that she uses her first language for personal and familial purposes while that English is her preferred language for communication with other peoples in society outside the home. Or in other side she may be largely monolingual in her first language only when she starts school (Alloway, T. P. 2006).

On the other hand, most of the students may be multilingual. Multilingualism is a phenomenon which described as bilingual may routinely use three languages or more than three languages. For expressing competence, a bilingual person may have very high levels of proficiency in both languages equally or may have only limited proficiency in one language than the other one. It can be concluded from discussions that the use of the term 'bilingual' is dependent upon some criteria's: the first one refer to the term context, the second term refer to linguistic proficiency and the third and last one is purpose.

In some cases when bilinguals are tired and unmotivated of their language or in situations if the person has not been using the language for a while or when one is speaking with someone else who has another status will become worse. The same situation can be happened in judging for the person if the person is bilingual or is not bilingual. Here it will be necessary to discussed if bilingual people are equally proficient and fluent in both of their languages because this is not the case. This type of language can be called dominant language. Dominant language is the language which tends to be the strongest one among others. It is crucial to remember that dominant language is not always the first language or native language of the bilinguals. It is natural that a bilingual can also be fluent in both of first and second languages without being able to function as a monolingual in either of their languages.

The bilingual persons are the persons who have the complete proficiency and ability of the language that introduce a person that are able to express elements in language of themselves simply. Also it is clear that language learners are considered as bilingual ones, however other researchers try to consider different degrees to show different people as bilingual individuals. Bilingualism can be considered on a spectrum with certain features. These features can be different for different people in various situations in all ages for all genders (Austin, E. 2005).

Modaresi (2014) believe that Bilingualism wholly refer to a state that a person is learned in a language other than individuals first language and bilingualism can be used about people and communities using two languages changeably for communications with each others. Native language or first language is learned by the person that speaks in that language, and grows up with that language, is in the touch with that language all the time in every situation and understands its social and cultural elements.

\section{RESEARCH QUESTIONS AND HYPOTHESES}

This study aims at investigating the effect of bilingualism on conflict regulation, cognitive control and recognition among primary school students.

The research questions are:

1- Will the bilingualism have a positive effect on the conflict regulation of the primary school students?

2- Will the bilingualism have effect on the cognitive control among primary school students?

3- Will the bilingualism have effect on the recognition control among primary school students?

And our null hypotheses are:

1- Bilingualism doesn't affect on conflict regulation, cognitive control and recognition among primary school students.

2- Bilingualism affect on conflict regulation, cognitive control and recognition among primary school students.

\section{METHODS}

The main aim of this study was to investigating the effect of bilingualism on conflict regulation, cognitive control and recognition among primary school students. In this chapter, the research questions and hypotheses related to this problem will be discussed. The mean scores of both the experimental and control group will be used to verify or reject the research hypotheses. To analyze the information gathered in the first part of descriptive statistics such as mean, standard deviation, etc., and the second part to test the hypotheses of multivariate analysis of variance (MANOVA) was used. The computer program called SPSS (Statistical Package for the Social Sciences) will be used since it has been admitted by many researchers in the field as being the best program used for the analysis of results.

\section{RESULTS AND DISCUSSION}

The main aim of this study was to investigating the effect of bilingualism on conflict regulation, cognitive control and recognition among primary school students. The main finding of the analysis shown in Tables indicated a positive answer to the major question of the study. It was found that the bilingualism had a direct effect on the students' conflict regulation, cognitive control and recognition. This was indicated by the high mean score that were calculated in the above tables. Specifically, the monolinguals performance was more differentiated than that the bilingual student's performance. The results of the study in the initial stages were shocking when comparing the performance of monolinguals in front of bilinguals. Another result of the research was its impact on developing student's conflict regulation, cognition and recognition control in primary school level. 


\section{Testing the Hypotheses and Answering the Research Questions}

In order to measure the effect of bilingualism on conflict regulation, cognitive control and recognition among primary school students a number of questions was raise. To answer these questions, this section will present the results of the statistical analyses of the information gathered such as mean, standard deviation, F percentage, median, etc., and test the hypotheses of multivariate analysis of variance (MANOVA).

The table 4.1 shows distribution of the population in the study. The sample consists of 120 students (60 boys and 60 girls), who were selected by random sampling. About fifty percent of students are girls and other fifty percent includes boys. In order to answer to the first question, "will the bilingualism have a positive effect on the conflict regulation of the primary school students?", the following analysis was calculated.

As the table 4.2 shows the mean of conflict regulation for monolingual students is $28 / 65$, and this score for bilingual students is $30 / 45$. The standard deviation of conflict regulation for monolinguals is $5 / 81$ and for bilinguals is $6 / 20$. And in order to answer to the second question," Will the bilingualism have effect on the cognitive control among primary school students?", the following descriptive analysis of students cognitive control was calculated.

The table 4.3 shows descriptive analysis of the cognitive control of students. As the table shows the mean of cognitive control for monolingual students is $38 / 80$, and this score for bilingual students is $42 / 27$. The standard deviation of cognitive control for monolinguals is 6/99 and for bilinguals is 4/95. And for answering to the last question," Will the bilingualism have effect on the recognition control among primary school students?", the next analysis was calculated.

The table 4.4 shows descriptive analysis of the recognition control of students. As the table 4.5 shows the mean of recognition control for monolingual students is $33 / 10$, and this score for bilingual students is $40 / 30$. The standard deviation of recognition control for monolinguals is 8/07 and for bilinguals is 7/98.

\section{CONCLUSIONS AND IMPLICATIONS}

The main goal of the study was to consider the effects of bilingualism on conflict regulation, cognitive control and recognition among primary school students. This study aimed to determine the relationship between being bilingual and its direct effect on student's conflict regulation, control of their cognition and recognition.

The main finding of the analysis in the previous section shown in Tables indicated a positive answer to the major question of the study. It was found that the bilingualism had a direct and positive effect on the students' conflict regulation, cognitive control and recognition. The high score of mean in the above tables was indicated this claim. As seen in above tables the monolinguals performance was more differentiated than the bilingual student's performance. To the best of our knowledge, this is the first study to examine the temporal aspects of bilingualism in relation to the conflict regulation, cognitive control and recognition of students in primary schools in bilingual areas.
Table 4.1. Distribution of the population

\begin{tabular}{llc}
\hline Gender & F & F percentage \\
\hline Girls & 60 & 50 \\
Boys & 60 & 50 \\
\hline
\end{tabular}

Table 4.2. Descriptive analysis of student's conflict regulation

\begin{tabular}{lccll}
\hline $\begin{array}{l}\text { Standard } \\
\text { deviation }\end{array}$ & mean & F & Language & Variable \\
\hline $81 / 5$ & $65 / 28$ & 60 & monolingual & $\begin{array}{l}\text { Conflict } \\
\text { regulation }\end{array}$ \\
$20 / 6$ & $45 / 30$ & 60 & bilingual & \\
\hline
\end{tabular}

Table 4.3. Descriptive analysis of student's cognitive control

\begin{tabular}{lccll}
\hline $\begin{array}{l}\text { Standard } \\
\text { deviation }\end{array}$ & Mean & F & Language & Variable \\
\hline $99 / 6$ & $80 / 38$ & 60 & Monolingual & $\begin{array}{l}\text { Cognitive } \\
\text { control }\end{array}$ \\
$95 / 4$ & $27 / 42$ & 60 & Bilingual & \\
\hline
\end{tabular}

Table 4.4. Descriptive analysis of student's recognition control

\begin{tabular}{lccll}
\hline $\begin{array}{l}\text { Standard } \\
\text { deviation }\end{array}$ & Mean & F & language & Variable \\
\hline $07 / 8$ & $10 / 33$ & 60 & Monolingual & $\begin{array}{l}\text { Recognition } \\
\text { control }\end{array}$ \\
$98 / 7$ & $30 / 40$ & 60 & Bilingual & \\
\hline
\end{tabular}

Table 4.5. Result of tests on conflict regulation, cognitive control and recognition of primary school students

\begin{tabular}{lcccll}
\hline $\begin{array}{l}\text { Ita } \\
\text { coefficient }\end{array}$ & Sig. & F & size & Statistic & Resource \\
\hline $188 / 0$ & $001 / 0$ & $47 / 7$ & $188 / 0$ & Pilayi & \\
$188 / 0$ & $001 / 0$ & $47 / 7$ & $812 / 0$ & Vilkezlamboda & Group \\
$188 / 0$ & $001 / 0$ & $47 / 7$ & $232 / 0$ & Hetling & \\
$188 / 0$ & $001 / 0$ & $47 / 7$ & $251 / 0$ & Roy & \\
\hline
\end{tabular}

Several pedagogical implications can be concluded from the results of this present study.

The following recommendations were made in the result of the study:

(1) It is recommended that a shift should be made from non-communicative ELT to communicative ELT;

(2) It is recommended that educational policy-makers should consider the possible effects that bilingualism may have in the students and their context of use;

(3) It is recommended that EFL teachers should receive instruction in how to teach to bilingual students;

(4) And it is recommended that teachers should be able to motivate students to speak the target language with other peoples and their classmates. 


\section{REFERENCES}

Alloway, T. P. (2006). How does working memory work in the classroom? Educational Research and Reviews. 1 (4), 134- 139.

Austin, E. (2005). Emotional intelligence and emotional information processing. Personality and Individual Differences, 39, 403-414.

Bull, R. Espy, K. A., \& Wiebe, S. A. (2008). Short-term memory, working memory, and executive functioning in preschoolers: Longitudinal predictors of mathematical achievement at 7 years. Developmental Neuropsychology; 33, $205-228$.

Barisi, A., \& Ghafari, O. (2006). Compparision of the information processing speed, working memory and emotion regulation of the monolingual and bilingual students. In- dian Journal of Fundamental and Applied Life Sciences ISSN: 2231-6345 (Online).

Modaresi, Y. (2014). Introduction to the Sociology of Language (Tehran: Institute for Humanities and Cultural Studies).

Thompson, R. A. (1991). "Emotional regulation and emotional development". Educational Psychology Review, 3, 269-307.

Tugade, M.M., Frederickson, B.L. (2002). Positive emotions and emotional intelligence. In: L. Feldman-Barrett \& P. Salovey (Eds.), the wisdom in feeling. New York: The Guilford Press. Pp. 319-340.

Yoo, S.H., Matsumoto, D., LeRoux JA. (2006). the influence of emotion recognition and emotion regulation on intercultural adjustment. Int J Intercult Relat, 30(5), 345-363. 